\title{
CRIAÇÃO DE UM PERCURSO DE APLICABILIDADE DO ENSINO PARA COMPREENSÃO NA EDUCAÇÃO FÍSICA ESCOLAR
}

Daiana Gomes Bento

Ivan Barbosa Silva

Nathalia Soares Rocha

Rodrigo Campos Camargo

Shirlei Arantes de Faria

Roberto Rocha Costa

\section{Resumo}

O objetivo deste trabalho e apresentar o Ensino para Compreensão, metodologia que ressalta as questões pedagógicas inseridas num processo de ensino-aprendizagem. São relatados neste estudo: $\mathrm{O}$ que e o Ensino para Compreensão, sua possibilidade na Educação Física Escolar e propostas de avaliação. Para isso, consideramos as idéias de vários autores que colaboraram para a materialização da nossa idéia de que compreender uma atividade requer muito mais do que executar alguns movimentos dentro do esporte, e preciso pensar nas atividades a serem passadas de forma que o aluno atinja a compreensão por meio de questionamentos que os farão compreender os problemas para que fisicamente possam resolvê-los de maneira mais fácil e natural.

\section{Palavras-Chaves}

Compreender; Pensar; Educação Física

\section{CREATION OF A PASSAGE OF APPLICABILITY OF EDUCATION FOR UNDERSTANDING IN THE PERTAINING TO SCHOOL PHYSICAL EDUCATION}

Daiana Gomes Bento

Ivan Barbosa Silva

Nathalia Soares Rocha

Rodrigo Campos Camargo

Shirlei Arantes de Faria

Roberto Rocha Costa

\begin{abstract}
The objective of this work is to present the teaching for understanding, a methodology that stands out the pedagogical questions inserted in a teach-learning process. Are told in this study: what it is education for understanding, his pertaining to school the Physical Education, proposals of evaluation. For this, we consider the ideas of some authors who had collaborated for the materialization of our idea of that to understand an activity requires much more of what inside executing some movements of the sport, she is necessary to think about the activities to be last of form that the pupil reaches the understanding by means of questionings that will make them to understand the problems so that physically they can decides them in easy and natural way but.
\end{abstract}

\section{Key-Words}

Understand; Think; Physical Education 


\section{INTRODUÇÃO}

A escola, como nos conhecemos, local de aprendizado, descobertas e crescimento intelectual, ha muito tempo vem passando por transformações no que diz respeito a metodologia de ensino. Propor uma nova abordagem pedagógica, fora dos padrões tradicionais, não e tarefa fácil, justamente porque questionaremos as formas de como ensinar as crianças a pensarem, e, alem disso, como fazer com que as crianças compreendam um conhecimento. Para isso usaremos a própria disciplina curricular, dando enfase ao que o aluno pensa e não somente o professor.

$\mathrm{O}$ ato de pensar, entre outras coisas, e o processo de fazer associates, de descobrir relações existentes na realidade e representa-las em nossa consciência. Já o ato de compreender, se da quando se e capaz de aplicar um conhecimento em uma nova situação, expandindo assim o processo de pensar, da consciência para a pratica.

Dentro deste contexto, situaremos nosso trabalho na proposta do Ensino para Compreensão e do Ensino de Jogos para Compreensão, alterando a maneira de pensar para implantar metodologias inovadoras que coloca o professor como agente reflexivo (que questiona ao invés de solucionar) dos conteúdos que o aluno deve vivenciar, e de que forma essa vivencia será oferecida e apresentada ao aluno. A teoria do Ensino de Jogos para Compreensão esta baseada no entendimento das situações táticas do jogo e fundamentalmente nas teorias do Construtivismo, pois nesta abordagem, o entendimento do jogo e o desenvolvimento de suas estratégias não dependem do desenvolvimento prévio de habilidades especificas o que facilita a Compreensão da estrutura do jogo por parte dos alunos.

Nossa intenção não e ter a pretensão de modificar ou criar um currículo, mas sim a de dar sugestões úteis da importância da Compreensão dos alunos perante os desafios de educar por meio dos esportes através dos temas abordados na disciplina de Educação Física.

\section{O ENSINO PARA COMPREENSÃO}

A teoria do Ensino para Compreensão alcançou maior expansão nos Estados Unidos, em 1988 na Universidade de Harward, cujá premissa surgiu da necessidade de ensinar levando os alunos a compreensão real do conhecimento. A proposta principal desta teoria e fornecer aos professores caminhos que os levem a gerar em seus alunos uma compreensão dos conteúdos de modo mais consistente. Segundo Pogre (2006), compreender e muito mais do que aprender, e uma forma mais profunda de se conquistar um conhecimento que potencializa o crescimento pessoal. Podemos dizer 
também que, se obtém compreensão de um determinado assunto quando se e capaz de aplicar o conhecimento adquirido em uma nova ocasião. Como a autora nos mostra:

E bom notar que nesta primeira aproximação da idéia de compreensão esta incluída uma dupla dimensão, que e intrínseca a este conceito: pensamento e ação, duas faces de uma mesma questão, duas dimensões que estão presentes em todo ato humano. Piaget define o pensamento como ação interiorizada. De acordo com essa linha, afirmamos que a compreensão implica em um sentido amplo, tanto simbólica como concretamente; não um mero ativismo, e sim ação do pensamento na ação, (POGRE, 2006).

Ao iniciarmos um estudo sobre o Ensino para Compreensão, alguns questionamentos de ordem pratica nos vem a tona, como: $\mathrm{O}$ que realmente queremos que nossos alunos compreendam? Como saber se meus alunos compreenderam? Como eles vão saber que compreendem?

Para a primeira questão, a autora nos propõe três elementos conceituais: fios condutores, tópicos produtivos e objetivos de Compreensão. E para as duas ultimas questões, outros dois elementos: desempenhos de Compreensão e avaliação diagnostica continua. Esses elementos conceituais entrelaçamse de maneira dinâmica e por esse motivo não segue uma trajetória linear, dando total liberdade para que o professor trace seus caminhos de acordo com suas necessidades e questionamentos (Pogre, 2006). A partir dessas idéias, podemos criar o seguinte quadro sinotico: 


\begin{tabular}{|c|c|c|c|}
\hline Elemento & Definição & Caracteristicas & Aplicação \\
\hline Fios condutores & $\begin{array}{l}\text { Questionamentos ou } \\
\text { grandes conceitos que } \\
\text { auxiliam o professor a } \\
\text { aplicar e manter a tarefa } \\
\text { por u m te mpo } \\
\text { prolongado. }\end{array}$ & $\begin{array}{l}\text { Funcionam como uma bússola, } \\
\text { que orienta o professor para que } \\
\text { ele não perca o foco da tarefa } \\
\text { que aplicou. }\end{array}$ & $\begin{array}{l}\text { Dividir com os estudantes } \\
\text { a escolhas dos fios condutores, } \\
\text { comprometendo-os a sua } \\
\text { própria aprendizagem. }\end{array}$ \\
\hline $\begin{array}{c}\text { Tópicos } \\
\text { produtivos }\end{array}$ & $\begin{array}{l}\text { Temas centrais em cada } \\
\text { area ou disciplina. }\end{array}$ & $\begin{array}{l}\text { Complexo, mas se torna } \\
\text { produtivo se for central dentro } \\
\text { da disciplina. Rico em } \\
\text { conexões com outros temas e } \\
\text { outras areas. }\end{array}$ & $\begin{array}{l}\text { Criar um leque de temas } \\
\text { relacionados entre si, onde o } \\
\text { tópico produtivo surgira onde } \\
\text { houver o maior numero de } \\
\text { conexões. }\end{array}$ \\
\hline
\end{tabular}

Objetivos de Profundidade e o alcance Orientação do percurso para se Ser exposto, claro e simples Compreensão que o professor se propõe chegar ao destino. para os alunos.

a atingir durante $o$ trabalho com o tópico.

Desempenhos de Atividades realizadas Interpretar, comparar, explicitar, Antecipar o tipo de atividade Compreensão pelos alunos que permitam relacionar, expor o que sabe por e criar ambientes diferentes a ele e ao professor algum meio. para que os alunos tenham perceber o que se de compreende. experimentar a Avaliação Acompanhamento do Permite voltar ao que foi Elaboração de uma matriz diagnostica processo crescente feito, repensar, produzir e estabelecendo uma lista de continua de autonomia em torno das incorporar novas perspectivas. critérios relativos a um compreensões. $\quad$ tópico e os graus de qualidade dos desempenhos esperados. (Pogre, 2005, p.49)

Com uma analise retrospectiva podemos ver a evolução e construção do sistema escolar, que vem sendo moldado paulatinamente de acordo com as necessidades, características de cada sociedade em determinada época e baseando-se em seus pilares como a economia e a política. Através dessa analise, percebemos que o avanço tecnológico das duas ultima décadas, modificaram toda a relação entre o sistema escolar e o sistema produtivo. Ao fim da década de setenta, onde se inicia uma crise econômica, instaurou um decréscimo produtivo que acabou com as expectativas individuais de 
crescimento social e questionou o papel da educação no desenvolvimento do país (POGRE, 2006). O que podemos constatar ao analisarmos os alunos em relação a aprendizagem, e a dificuldade de correlação entre os conteúdos aprendidos na escola e suas necessidades fora do âmbito escolar. A esse respeito, podemos dizer que a teoria do Ensino para Compreensão nos propõe meios para corrigir essa deficiência, um deles seria o fato de que baseada nas teorias construtivistas, o professor deve levar sempre em conta toda a bagagem intelectual e motora que o aluno trás consigo, e, a partir desses princípios, contextualizar os conteúdos de sua disciplina se entendermos que o aprendizado se faz através de relações.

Diante dessas afirmações, podemos perceber tamanha importância do ato de se trabalhar e incentivar a Compreensão nos alunos dentro do âmbito escolar para que essa pratica seja transmitida fora dele. As novas abordagens pedagógicas, como o Ensino para Compreensão, vem avançando em uma maneira diferente de ensinar, por meio dele o professor realiza "uma nova aula", fazendo com que os alunos aprendam mais a partir dos seus conhecimentos, realizando assim situações problemas a serem resolvidas pelos alunos, não se esquecendo de que somos seres diferenciados pelos nossos potenciais, portanto, aprendemos por caminhos diferentes, basta que o professor realize atividades que tenham relação com a realidade do aluno, traçando diferentes rotas de acesso ao conhecimento, que serão estabelecidas pelas próprias capacidades e habilidades que os alunos dominam.

Nas aulas elaboradas pelo professor, o lúdico tem grande valor, o docente não necessita de técnicas e métodos, mais pode dar oportunidade aos alunos que dêem tópicos sobre as atividades que queiram aprender, assim, fazendo-os refletir e praticar. Sempre que um tópico for levantado, o professor pode transformar e adaptar, ligando aos seus interesses.

[...] os professores devem propor atividades que sejam compatíveis com o nível de habilidade dos alunos, e assim, através de desafios táticos eles são levados a obter sucesso durante todo o processo de aprendizagem do jogo, sentindo-se competentes a cada passo. Para isso, o professor pode e deve modificar os jogos, alterando suas regras e equipamentos[...] (POGRE, 2006).

O Ensino para compreensão também auxilia no processo de motivação dos alunos diante dos conteúdos abordados nas aulas, pois, ao se estabelecer uma determinada atividade em conjunto com os discentes, estes se sentem responsáveis pelo bom andamento da aula, já que tiveram a liberdade de poder se expressar e opinar sobre o tópico a ser estudado e discutido, tornando-os mais participativos, perceptivos e criativos. 


\section{O ENSINO PARA COMPREENSÃO NA EDUCAÇÃO FÍSICA ESCOLAR}

A educação física escolar e um campo importante na construção da criança por englobar aspectos sociais, cognitivos, culturais e motores.

A consciência do corpo permite que a criança descubra com o tempo as diversas formas de explorar a sua corporeidade através das praticas esportivas, sendo assim, é importante que o educando passe por desafios táticos onde são levados a obter desafios em busca da Compreensão durante todo o processo de aprendizagem.

Segundo BASTOS e BRITO (2004, p. 263), "A corporeidade a luz do pensamento complexo permite compreender o ser humano como ser complexo, estando todas as qualidades e dimensões pertencentes ao humano enraizados em seu corpo".

Isso nos leva a uma discussão sobre como superar o modelo de pensamento do ensino tradicional que esta impregnado no modo de realizarmos as atividades pedagógicas nas aulas de Educação Física.

A metodologia do Ensino para a Compreensão na Educação Física Escolar nos atenta para o fato de que em todas as atividades existem questionamentos onde os alunos são estimulados a responder. A todo o momento e principalmente frente aos problemas, o professor devera elaborar desafios em relação as atividades em questão, instigando os alunos a descobrirem uma solução.

O objetivo da Educação Física na abordagem do Ensino para a Compreensão e trabalhar a reflexão dos conteúdos dando ênfase a nossa metodologia de forma teórica e pratica para que possamos romper com os métodos tradicionais e manifestar dentro da escola uma maneira diferente de ensinar, estudar e aplicar novas propostas de ensino e realizar o trabalho onde o principal seja o sujeito a ser educado.

\section{UMA PROPOSTA DE AVALIAÇÃO NO ENSINO PARA COMPREENSÃO EM EDUCAÇÃO FÍSICA}

O desenvolvimento do pensar ou raciocinar não se detêm apenas no momento em que o professor aplica a matéria, através de suas explicates nem somente na participação dos alunos, mas também faz parte desse desenvolvimento, melhor dizendo, completando-o, a avaliação.

A avaliação e uma ferramenta de grande importância no processo de ensino aprendizagem, buscando sempre observar a evolução da Compreensão do aluno no que se refere as propostas ditadas pelo 
professor em sala de aula. Esta não serve apenas como teste de conhecimento como e encarado por alguns, onde, o aluno reproduz de forma escrita, multipla-escolha, ou pratica o que foi transmitido pelo professor. Mas muito mais do que isso, é a forma que o aluno que se encontra frente a um problema, tendo que obrigatoriamente buscar soluções para resolvê-lo, se fazer pensar, refletir, raciocinar e não somente lembrar, como se tivesse decorado o que foi dito em sala de aula pelo professor.

Nesta abordagem, a avaliação tem por objetivo reforçar os concertos ${ }^{1}$ formados pelos alunos nas suas individualidades no que se refere a Compreensão destes pelo tema proposto, onde, se discute uma proposta avaliativa coerente com o ensino para Compreensão. "A aprendizagem não e simplesmente armazenar e gravar conhecimentos alheios, mas aprender e a percepção da própria situação de vida como um problema e a solução desse problema na reflexão e ação" (KUNS, 2001 p. 154).

\section{A IMPORTÂNCIA DO ESCLARECIMENTO DO PROPÓSITO DA AULA}

O professor por sua vez, tem a obrigação de "prestar contas" a instituição em que trabalha, "ele tem que dar a nota" para que se de seqüência as operações de praxe da instituição. Porem, não e sempre dessa forma que a avaliação e vista e sentida pelos alunos. Segundo Coll (1999 p. 35), naturalmente, se um aluno não conhece o propósito de uma tarefa e não pode relacionar esse propósito a Compreensão daquilo que implica a tarefa e as suas próprias necessidades, muito dificilmente poderá realizar aquilo que o envolve em profundidade.

São obvias as necessidades da existência de clareza nos objetivos das aulas propostas, sendo que, com os objetivos definidos pelo educador e entendidos pelos alunos, a assimilação das mesmas, será de grande facilidade. Por exemplo:

Tópico produtivo: Futebol / Objetivos: Desenvolver o passe na sua forma tática:

Fios Condutores: Passe: Para que serve o passe? Por que fazer o passe? Quando fazer o passe?

Quais os diferentes tipos de passe? De que forma fazer e qual a hora certa de usar determinado passe?

No momento da avaliação, depois de respondidas estas questões, os alunos com os objetivos em mente,

${ }^{1}$ Lipman apud RODRIGUES, Zuleide Blanco. Conceito: Resultado final de um conjunto de informações e as relações que lhes são pertinentes. 
conseguirão explicar de forma plausível qualquer questão referente ao passe no futebol ou em qualquer outro esporte que utilize desse fundamento, alem de suas funções e tipos. Já para a aplicação dessa avaliação, entramos em outra questão: de que forma fazer?

Dentro da abordagem do Ensino para Compreensão (EpC), o propósito da avaliação e de que o aluno compreenda conceitos, temas e idéias, habilitando-se a utilizar desse conhecimento em outras situações, refletindo sobre seu próprio processo de aprendizagem e não focar apenas nos resultados. Para melhor avaliação de seus alunos e imprescindível que o educador tenha em mente os enfoques atribuídos por Entwistle apud Coll (1999 p. 35):

Enfoque profundo: intenção de compreender; forte interação com o conteúdo; relação de novas idéias com o conhecimento anterior; relação de conceitos com a experiência cotidiana; relação de dados com conclusões; exame da lógica dos argumentos.

Enfoque superficial: intenção de cumprir os requisites da tarefa; memorização da informação necessária para provas ou exames; a tarefa e encarada como imposição etema; ausência de reflexão sobre os propósitos ou estratégia; foco em elementos soltos, sem integração; os princípios não são distinguidos a partir de exemplos.

Por meio desses enfoques, o professor poderá direcionar melhor suas aulas e avaliações, já que ambos permitem ser trabalhados. A proposta de avaliação que sugerimos ao educador e a da avaliação por observação diária. Esta proposta e uma forma interessante de avaliação, já que utiliza a observação diária do desenvolvimento qualitativo do avaliado. O professor avalia seus alunos através de questionamentos pertinentes ao tema abordado pelo mesmo, observando a complexidade das questões as suas respectivas respostas, tudo isso, no próprio momento do processo de ensino aprendizagem.

Para dar auxilio a proposta, sugerimos também a criação de uma comunidade investigativa, que conforme Lipman (1995, p 31), esta e formada por estudiosos, por intermédio de procedimentos semelhantes no desenvolvimento de objetivos idênticos. Em outras palavras, o educador deve escolher temas problemáticos a fim de prender a atenção do aluno. Este por sua vez usando de suas atribuições cognitivas, juntamente com seus colegas busca responder a estas questões.

Ainda segundo Lipman (1995 p 31), converter a sala de aula em uma comunidade de investigação na qual os alunos dividem opiniões com respeito, desenvolvem questões a partir das idéias de outros, 
desafiam-se entre si para fornecer razoes a opiniões ate então não apoiadas, auxiliarem uns aos outros ao fazer inferências daquilo que foi afirmado e buscar identificar as suposições de cada um.

\section{UM EXEMPLO DE APLICABILIDADE DA AVALIAÇÃO}

Utilizando-se do exemplo já citado do esquema de tópico produtivo, objetivo e fios condutores, segue abaixo uma sugestão de aplicabilidade de avaliação por observação diária por meio de comunidade de investigação.

$\mathrm{Na}$ aula, os alunos são apresentados aos temas e seus objetivos. E lançada uma atividade onde os alunos praticam o jogo de futebol normalmente, porem, com algumas alterações. Por exemplo: o time que estiver com a bola, terá de trocar no mínimo cinco passes entre seus integrantes para chegar ao gol adversário, sem permitir que o mesmo roube a posse da bola. Se isso ocorrer e a primeira equipe recupera-la a contagem reiniciara do zero. O jogo de futebol envolve os alunos ate o momento em que o professor reúne o grupo para discutir sobre alguns dos fios condutores. E quando entra a comunidade de investigação. Os alunos reúnem-se em grupos ou toda turma para pensar nas dificuldades, facilidades e táticas utilizadas para a realização da atividade, e são avaliados no mesmo momento, não pelos resultados das respostas, mas sim pelas formas utilizadas para chagar a tal conclusão e pela evolução de seu conhecimento num determinado período de tempo.

\section{DOS REGISTROS}

Outra preocupação que atinge vários professores e de como fazer o registro dessas avaliações. Neste trabalho, propomos o uso do portfolio. Este, um documento no qual, contem vários produtos de avaliação, trabalhos e sugestões, (esta ultima feitas pelos professores). Veremos a seguir, a forma de se montar um portfolio.

\section{O PORTFOLIO PARA REGISTRO}

O registro de toda e qualquer atividade ministrada em sala, deve sempre existir, pois, e através deste, que o professor tem o controle e ordem dos conteúdos apresentados, e sobre o rendimento dos alunos em termos de aprendizado, e como não poderia deixar de ser, a avaliação inclui-se perfeitamente nesse documento.

Para construir um portfolio, serão necessários o cumprimento de quatro itens essenciais, sendo eles: conteúdo, organização do tempo, estrutura, e envolvimento dos alunos. 


\section{CONTEÚDO}

POGRE (2006, p. 115), nos traz que, o conteúdo do portfolio depende do seu propósito e da serie envolvida, ou seja, continuando com o exemplo do futebol, onde propomos a Compreensão do fundamento "passe", supondo que esse fundamento fosse trabalhado com as turmas do $1^{\circ}$ e $2^{\circ}$ anos do ensino fundamental, cujo conteúdo constara o desenvolvimento da reflexão dos alunos, e será composto por textos, desenhos e reflexões dos alunos em conjunto com os professores.

\section{ORGANIZAÇÃO DO TEMPO}

Para uso do professor, este item tem como objetivo guiar suas observações através dos dados contidos, tais como as evoluções ou equívocos gerados ao longo do período de avaliação proposto. E de suma importância que o professor também inclua em sua rotina com os alunos um espaço sistemático de reflexão e organização do portfolio.

\section{ESTRUTURA}

A estrutura do portfolio deve conter: Introdução; Descrição breve das tarefas; Datação das atividades acrescentadas; Marcação, com etiquetas que distinguem as soluções iniciais do relatório final; Sessões de revisão contendo as reflexões dos alunos, auto-avaliação; Comentários dos professores, dos colegas e especialistas na atividade proposta.

\section{ENVOLVIMENTO DO ALUNO}

O envolvimento do aluno esta presente na criação e confecção, escolha dos temas presentes em tal documento, inserção de dados e no processo de avaliação que constara os motivos de sucesso e insucesso de seu aprendizado e os conjuntos para aprimorar o trabalho.

Para trabalhar o portfolio, o professor apresentara uma pasta aos seus alunos esclarecendo sua finalidade e intenção. Ao fazer isso, compartilha com o aluno a responsabilidade do processo de avaliação, trazendo para os mesmos, uma nova perspectiva no momento de serem avaliados.

\section{CONCLUSÃo}

Em nosso trabalho buscamos discutir a questão da Compreensão, do pensar e principalmente do entendimento das propostas de ensino a partir das práticas pedagógicas sugeridas com uma abordagem pedagógica ousada como Ensino para Compreensão nas aulas de Educação Física. 
O esporte e um grande aliado que leva as crianças e adultos a reflexão para ação educativa justamente por ser tão plural e possuir fortes significados e re-significados atribuídos a ele juntamente com as diversificações do caráter humano que, quando estimulado, consegue compreender e pensar na sua condição e formação humana. Na escola encontramos espaço para todos os tipos de manifestações das praticas esportivas, e nas aulas de Educação Física reforçamos a idéia de dar ao esporte um tratamento pedagógico.

\section{REFERÊNCIAS}

COLL, C. O construtivismo na sala de aula. São Paulo: Ática, 1999.

KUNS, E. Didática da Educação Física (Org.). São Paulo: Ed. da Unijui, 2001.

LIPMAN, M. O pensar na educação. Petrópolis: Vozes, 1995.

POGRE, P.; LOMBARDI, G. O ensino para a compreensão. São Paulo, Hoper, 2006.

RAPPAPORT, C. R.; FIORI, W. R.; DAVIS, C. Psicologia do desenvolvimento: teorias do desenvolvimento, conceitos fundamentais. São Paulo: EPU, 1981.

RODRIGUES, Z. B. Desenvolvendo habilidades básicas de pensamento: possibilidades de reflexão e pensar correto.

SCAGLIA, A. J. O futebol que se ensina e o futebol que se aprende. 1999. Dissertação (Mestrado) Faculdade de Educação Física, Universidade Estadual de Campinas, Campinas, 1999.

SOARES et al. Metodologia do ensino da Educação Física. São Paulo: Cortez, 1992. 


\title{
Daiana Gomes Bento
}

UNIMÓDULO - Centro Universitário

\author{
Ivan Barbosa Silva \\ UNIMÓDULO - Centro Universitário
}

\section{Nathalia Soares Rocha \\ UNIMÓDULO - Centro Universitário}

\section{Rodrigo Campos Camargo \\ UNIMÓDULO - Centro Universitario}

\section{Shirlei Arantes de Faria \\ UNIMÓDULO - Centro Universitario}

\section{Roberto Rocha Costa}

UNIMODULO - Centro Universitario e orientador do GEPEEFE.

\section{Referência do artigo:}

\section{ABNT}

BENTO, D. G. et. al. Criação de um percurso de aplicabilidade do ensino para compreensão na educação física escolar. Conexões, v. 6, p. 355-366, 2008.

\section{APA}

Bento, D. G., Silva, I. B., Rocha, N. S., Camargo, R. C., Faria, A. S., \& Costa, R. R. (2008). Criação de um percurso de aplicabilidade do ensino para compreensão na educação física escolar. Conexões, 6 , 355-366.

\section{VANCOUVER}

Bento DG, Silva IB, Rocha NS, Camargo RC, Faria AS, Costa RR. Criação de um percurso de aplicabilidade do ensino para compreensão na educação física escolar. Conexões, 2008; 6: 355-366. 